\title{
Two Body Wear Characteristics of Polyalthia Longifolia/Mangifera Indica/Jute Fiber Reinforced Epoxy Composites using Taguchi Technique
}

\author{
Srinivas Shenoy Heckadka ${ }^{a}$ (D), Suhas Yeshwant Nayak ${ }^{a *}$ (1), Sathish Rao ${ }^{a}$, Rashmi Samant", \\ Shrinidhi L. Ka, Krishna Manoj Salunkhe ${ }^{a}$ \\ ${ }^{a}$ Manipal Academy of Higher Education, Manipal Institute of Technology, Department of Mechanical
and Manufacturing Engineering, Manipal, Karnataka, 576104, India
}

Received: July 18, 2020; Revised: December 21, 2020; Accepted: January 14, 2021

\begin{abstract}
This research work investigates the two body wear behavior of natural fiber reinforced composites using a pin on disc test set-up. Natural fibers such as Polyalthia Longifolia, Mangifera Indica and Jute were used as reinforcements with epoxy matrix. Four types of composites with $30 \%$ fiber weight fraction were fabricated using hand layup and compression molding technique. Taguchi experimental design with $\mathrm{L}_{16}$ orthogonal array was considered. Four factors viz. fiber type, normal load, sliding speed and sliding distance at four levels were analyzed for obtaining minimum specific wear rate. Normal load was the most significant factor influencing the response with percentage contribution of $56.21 \%$ while the least contribution was the factor sliding speed (2.30\%). Based on the optimum combination, confirmation experiments were conducted, the results of which were obtained with a minimal error of 4.64\%. Micrographs revealed different wear mechanisms like fiber-matrix de-bonding, fiber pull-out, matrix cracking, furrows and crater formation.
\end{abstract}

Keywords: Polyalthia Longifolia, Mangifera Indica, Jute, Epoxy, Taguchi, Sliding wear, Scanning Electron Microscopy.

\section{Introduction}

Composites are combination materials with at least two distinct phases, i.e. matrix and reinforcement that are combined to form the material. Composites are employed for several purposes including construction, automotive parts, furniture, packaging, aircraft body etc. Reinforcements used in composites are either natural or synthetic. Steep depletion in petroleum resources, rising global concern about the environment and upcoming environmental regulations set by governments around the world has paved the way for research and application of natural fibers in materials around us over synthetic alternatives ${ }^{1-4}$. Natural fibers are found to be lightweight, abundant, low cost, acoustic insulating, renewable, non-toxic, bio-degradable and recyclable, making them a great alternative reinforcement in composite materials. The most recent discoveries in natural fibers have indicated an energy-saving potential in addition to the green and renewable characteristics ${ }^{5,6}$. This is because minimal effort goes into processing raw natural fibers into commercially viable form in comparison to their synthetic alternatives?

Natural reinforcements can be broadly classified as animal-derived, mineral-based and plant-based fibers. Animal-derived fibers include silk, wool, horsehair and goat hair8. Mineral derivatives include basalt, fibrous brucite and wollastonite ${ }^{9-11}$. Plant based natural fiber composites are garnering a lot of attention among the researchers because of advantages they bring over synthetic fiber reinforced composites which include reduced health effects on humans

*e-mail:synayak@gmail.com and environment friendly. Also, natural fibers in composites, cause reduced tool wear while machining composites. Natural fiber composites being light in weight are finding applications in wide range of industries like automobile, construction, plastics, bio-medical, etc ${ }^{12}$. Plant-based fibers range from cotton, bamboo, jute, hemp, kenaf, ramie, coir, sisal, date palm ${ }^{13-16}$, to considerably rare but upcoming species like Polyalthia Longifolia, Mangifera Indica, Palmyra, Calotropis Procera, Grewia Serrulata, Cyperus Pangorei, Phoenix SP., Grewia optiva, Bauhinia Vahlii, Himalayan Nettle and Himalayan Agave fibers, which are abundantly available and have lasting positive effects on the nature ${ }^{17-28}$.

Visualization of tribological applications of polymeric composites has paved the way for increased research and improvement in the wear resistance and behavior of composites. Wear is a measure of the degree of damage to a solid surface in which there is removal of material over a period of time. This phenomenon is caused due to relative motion between two surfaces ${ }^{29}$. Friction and wear contributes $23 \%$ to the annual global energy consumption of which $20 \%$ goes into lubrication to prevent wear, and the other $3 \%$ goes into the replacement of machines damaged by wear ${ }^{30}$.

Wear is proportional to operating parameters and inversely to the presence of reinforcement ${ }^{31}$. Study of tribological properties of polyester oil palm fiber reinforced composites showed three to four times enhancement of wear properties in contrast to neat polyester polymers ${ }^{32}$. Studies based on hybrid natural-synthetic composites display better wear properties in contrast to pure synthetic composites. An 
epoxy hybrid of 15 wt.\% glass fiber and 5 wt.\% Calotropis Procera fiber showed lesser loss due to wear than 20 wt. $\%$ glass fiber reinforced composite ${ }^{21}$. Similar studies were conducted on Himalayan nettle fibers, Cyperus Pangorei, Grewia Serrulata fibers and Palmyra fibers wherein they displayed improved wear resistance in comparison to neat polymers ${ }^{18,22,23,26}$. Novel fibers are being studied extensively by researchers with a focus on reducing hazards on the environment and thereby by providing an opportunity to improve rural economy, especially in developing countries. Research has shown that use of more than one type of fiber in the composites come with enhanced properties prompting researchers to explore hybridization of composites with novel and proven natural fibers ${ }^{33-36}$. From literature survey, it is evident that very little information exists on the wear properties of Polyalthia Longifolia and Mangifera Indica fiber based composites and also with respect to the effect of fiber type and other variables on the wear rate of natural fiber reinforced composites. Hence, this study broadens into analysis and study of influence of fiber type, normal load, sliding distance, sliding speed on the wear properties of the composite and categorizes them on the basis of most significant to the least significant. To draw a comparison, jute fiber which is well researched is considered along with Polyalthia and Mangifera fibers as reinforcements in an epoxy matrix. These studies enable humankind to be effective in preserving the nature for posterity and engage in sustainable practice.

\section{Materials and Methods}

\subsection{Materials}

The jute fibers used in this study were commercially procured from M/s Achu Fibers, Erode, Tamil Nadu, India. They were treated with $0.5 \mathrm{wt} . \% \mathrm{NaOH}$ for $24 \mathrm{~h}^{37}$ to improve structural integrity and to remove the dead cells from the outer layers of the fibers. Polyalthia Longifolia and Mangifera Indica leaves were collected from plantations in Manipal, Karnataka state of India. The leaves were allowed to dry for two weeks. The dried leaves were then soaked in distilled water to facilitate easy removal of leaf material bound around the mid-rib. The mid rib-fibers were later dried in a hot air oven at $40{ }^{\circ} \mathrm{C}$ for $6 \mathrm{~h}$. to remove moisture. Polyalthia fibers were subjected to mercerization for $6 \mathrm{~h}$ with $5 \mathrm{wt} . \% \mathrm{NaOH}$ followed by repeated washing with water and neutralization with 2.5 wt. $\%$ hydrochloric acid ${ }^{28}$. The Mangifera fibers were treated with 15 wt. $\% \mathrm{NaHCO}_{3}$ for $18 \mathrm{~h}$ followed by neutralization process as adopted for the Polyalthia fibers. All the fibers after the treatment were dried in a hot air oven for $1 \mathrm{~h}$ at $40^{\circ} \mathrm{C}$. TAPPI protocol was adopted to estimate the proportion of cellulose, hemicellulose and lignin in the treated fibers. Three set of each fiber was used in the determination of the chemical constituents ${ }^{38}$.

\subsection{Fabrication of composites}

Composite panels were fabricated with the above discussed fibers and Epoxy Bisphenol-12 (Lapox - L12) and Triethylene Tetro Amine (Lapox K6) as matrix material using hand layup method in a mold having a pocket of $300 \mathrm{~mm}$ x $300 \mathrm{~mm}$. The mold with the laid up composite was later pressed in a compression molding machine. Fiber weight fraction of $30 \%$ was maintained in all the composites. A hybrid composite was fabricated by using all the three types of fibers in equal proportion leading to a fiber weight fraction of $30 \%$. Designation and compositional details are presented in Table 1. The resin and hardener were supplied by Atul Ltd., India. Samples for wear testing of were prepared using a jigsaw cutter. Test samples had a square cross section of $4 \mathrm{~mm} \times 4 \mathrm{~mm}$ with a length of $40 \mathrm{~mm}$. Densities of all the composites were determined with a digital density balance (Make: Contech; Model: CAS-234) ${ }^{39}$

\subsection{Wear testing}

Wear tests were conducted on Pin on Disc apparatus of DUCOM make (Model: TR-201C). The tests were conducted as per the ASTM G99 standard for dry sliding wear ${ }^{40,41}$. A graphical representation of the methodology is presented in Figure 1.

The parameters considered for the testing were sliding distance range of $500 \mathrm{~m}, 1000 \mathrm{~m}, 1500 \mathrm{~m}$ and $2000 \mathrm{~m}$. The sliding speed was set between $0.6 \mathrm{~m} / \mathrm{s}$ and $2.4 \mathrm{~m} / \mathrm{s}$ with an increment of $0.6 \mathrm{~m} / \mathrm{s}$ while the loading was placed between 1 to $4 \mathrm{~kg}$ in increment of $1 \mathrm{~kg}$. Mass of the specimen before and after each wear test was determined using a precision weighing balance (Make: Essae; Model: FB-300). Specific Wear Rate (SWR) was then arrived at by using Equation $1^{42}$.

$$
\frac{m_{i}-m_{f}}{\rho \times d_{s} \times L_{n}}
$$

where, $\mathrm{m}_{\mathrm{i}}=$ mass of the specimen before wear $(\mathrm{g})$

$\mathrm{m}_{\mathrm{f}}=$ mass of the specimen after wear $(\mathrm{g})$

$\rho=$ density of the composite $\left(\mathrm{g} / \mathrm{mm}^{3}\right)$

$\mathrm{d}_{\mathrm{s}}=$ sliding distance $(\mathrm{m})$

$\mathrm{L}_{\mathrm{n}}=\operatorname{normal}$ load $(\mathrm{kg})$

\subsubsection{Design of Experiments}

The experiments were designed with Taguchi's approach which is a systematic method to set parameters whenever an experiment involves a large number of variables. The set of

Table 1. Designation and composition of various composites

\begin{tabular}{lccccc}
\hline \multicolumn{1}{c}{ Fibers } & $\begin{array}{c}\text { Designation of } \\
\text { fibers }\end{array}$ & $\begin{array}{c}\text { Designation of } \\
\text { composites }\end{array}$ & FWF (\%) PF & FWF (\%) JF & FWF (\%) MF \\
\hline Polyalthia Longifolia & PF & PC & 30 & - & - \\
\hline Jute & JF & JC & - & 30 & - \\
\hline Mangifera Indica & MF & MC & - & - & 30 \\
\hline $\begin{array}{l}\text { Polyalthia Longifolia + Jute + Mangifera } \\
\text { Indica }\end{array}$ & HF & HC & 10 & 10 & 10 \\
\hline
\end{tabular}




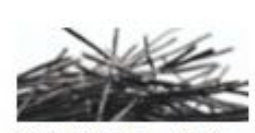

Polyalthia Longifolia fibers treated with $\mathrm{NaOH}$

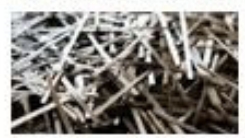

Mangifera fibers treated with $\mathrm{NaHCO}$ s

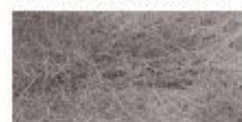

Jute fibers treated with $\mathrm{NaOH}$
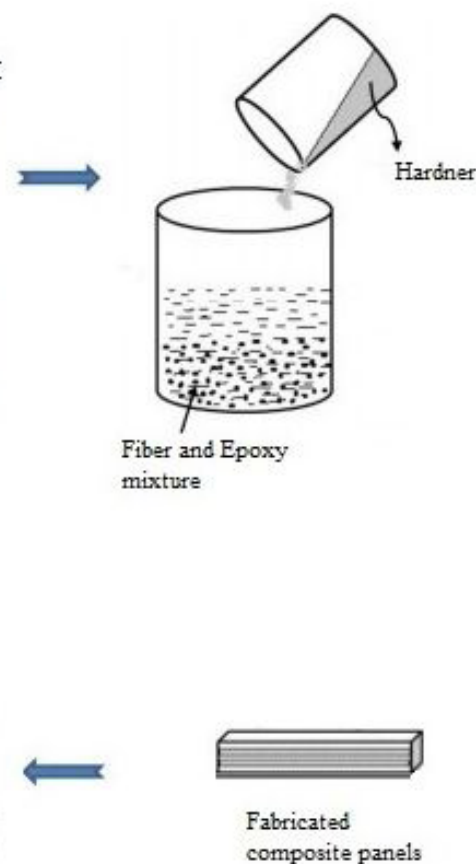

composite panels

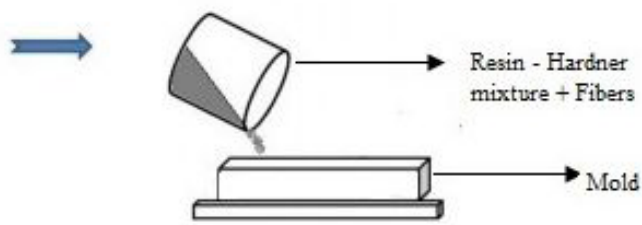

$\downarrow$

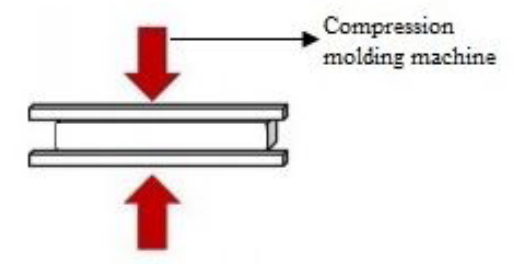

Consolidation of

composite panel

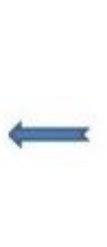

Wear test using

Pin on Disc

Machine

Figure 1. Graphical representation of the methodology.

Table 2. Different factors and associated levels.

\begin{tabular}{lcccc}
\hline \multicolumn{1}{c}{ Factors } & Level 1 & Level 2 & Level 3 & Level 4 \\
\hline Fiber 'A' & PF & JF & MF & HF \\
\hline Normal load 'B'(kg) & 1 & 2 & 3 & 4 \\
\hline Sliding speed 'C' (m/s) & 0.6 & 1.2 & 1.8 & 2.4 \\
\hline Sliding distance 'D' $(\mathrm{m})$ & 500 & 1000 & 1500 & 2000 \\
\hline
\end{tabular}

predetermined rules determine the steps to be followed to ascertain the detrimental variables to any experiment and how they are supposed to be varied with respect to each other. This approach gives scope for sufficient planning before execution and prevent loss of material and energy in trial basis experimentation ${ }^{43}$. The factors and levels are shown in Table 2. A standard $\mathrm{L}_{16}$ orthogonal array with 4 factors and 4 level was used and is presented in Table 3. Response calculations were based on the specific wear rate.

Outcome of any process depends on parameters which influences it. The one's which can be controlled are known as control factors while the uncontrollable one's are known as noise. Noise are those factors which cannot be controlled during the process but are controllable during the experiment. Taguchi's approach helps in determining the control factors and thereby help in minimizing variability in the process. Experiments designed using Taguchi's approach uses a twostep optimization process. Firstly, S/N ratio (Signal to Noise ratio) is used to determine the control factors followed by identifying the control factors which will bring the mean to the target having negligible or zero effect on the $\mathrm{S} / \mathrm{N}$ ratio as a second step. $\mathrm{S} / \mathrm{N}$ ratio measures the variation of the response i.e. output, in relation to the target value under different noise conditions. Out of the three quality characteristics available with reference to $\mathrm{S} / \mathrm{N}$ ratio, "smaller the better" is considered ${ }^{44}$, the mathematical expression of which is given by Equation $2^{45}$.

$$
\frac{S}{N}=-10 \log \frac{1}{n}\left(\sum y\right)^{2}
$$

where, $\mathrm{y}=$ observed data

$\mathrm{n}=$ number of observation

\subsection{Morphological studies}

Scanning Electron Microscopy (SEM) (Make: Zeiss; Model: EVO 18 Special edition) was employed to assess the damage surface and understand the various mechanisms of wear. Specimen was coated with Gold/ Palladium before mounting them in the vacuum chamber. The SEM was operated under variable pressure mode and at an accelerating voltage of $15 \mathrm{kV}$. 


\section{Results and Discussion}

\subsection{Chemical constituents of natural fibers}

The chemical constituents of the treated fibers are presented in Table 4. Cellulose content was the highest in all the three fibers but was found to be significantly more in case of jute fibers followed by polyalthia and mangifera fibers. Relatively high amount of hemicellulose was seen in polyalthia fibers while in case of mangifera and jute fibers they were found to be alike. Proportion of lignin was the least among the three constituents determined, in polyalthia and mangifera fibers but in jute fibers its proportion was seen to be slightly higher than the others.

\subsection{Specific Wear Rate}

Results of specific wear rates (SWR), considering four different factors and their respective levels are presented in Table 5. All the experiments were replicated thrice to calculate the average SWR. The minimum SWR

Table 3. Taguchi $\mathrm{L}_{16}$ orthogonal array for designed experiments.

\begin{tabular}{|c|c|c|c|c|c|}
\hline \multirow{2}{*}{ Experiment No. } & \multirow{2}{*}{$\begin{array}{c}\text { Combination of } \\
\text { factors and levels }\end{array}$} & \multicolumn{4}{|c|}{ Factors } \\
\hline & & $\mathrm{A}$ & $\mathrm{B}$ & $\mathrm{C}$ & $\mathrm{D}$ \\
\hline 1 & A1B1C1D1 & $\mathrm{PF}$ & 1 & 0.6 & 500 \\
\hline 2 & A1B2C2D2 & $\mathrm{PF}$ & 2 & 1.2 & 1000 \\
\hline 3 & A1B3C3D3 & $\mathrm{PF}$ & 3 & 1.8 & 1500 \\
\hline 4 & A1B4C4D4 & $\mathrm{PF}$ & 4 & 2.4 & 2000 \\
\hline 5 & A2B1C2D3 & JF & 1 & 1.2 & 1500 \\
\hline 6 & A2B2C1D4 & JF & 2 & 0.6 & 2000 \\
\hline 7 & A2B3C4D1 & JF & 3 & 2.4 & 500 \\
\hline 8 & A2B4C3D2 & JF & 4 & 1.8 & 1000 \\
\hline 9 & A3B1C3D4 & MF & 1 & 1.8 & 2000 \\
\hline 10 & A3B2C4D3 & $\mathrm{MF}$ & 2 & 2.4 & 1500 \\
\hline 11 & A3B3C1D2 & MF & 3 & 0.6 & 1000 \\
\hline 12 & A3B4C2D1 & MF & 4 & 1.2 & 500 \\
\hline 13 & A4B1C4D2 & $\mathrm{HF}$ & 1 & 2.4 & 1000 \\
\hline 14 & A4B2C3D1 & $\mathrm{HF}$ & 2 & 1.8 & 500 \\
\hline 15 & A4B3C2D4 & $\mathrm{HF}$ & 3 & 1.2 & 2000 \\
\hline 16 & A4B4C1D3 & $\mathrm{HF}$ & 4 & 0.6 & 1500 \\
\hline
\end{tabular}

Table 4. Chemical constituents of treated fibers

\begin{tabular}{lccc}
\hline \multirow{2}{*}{ Content } & \multicolumn{2}{c}{ Fibers } & JF \\
\cline { 2 - 4 } & PF & MF & $71.40-75.32$ \\
\hline Cellulose \% & $32.06-38.66$ & $44.02-54.16$ & $8.15-9.24$ \\
\hline Hemicellulose \% & $21.81-23.42$ & $8.41-14.51$ & $10.32-11.38$ \\
\hline Lignin \% & $8.26-10.63$ & $8.72-11.60$ & \\
\hline
\end{tabular}

Table 5. Specific Wear Rate of all experiments.

\begin{tabular}{|c|c|c|c|c|c|c|}
\hline \multirow{2}{*}{ Experiment No. } & \multirow{2}{*}{$\begin{array}{c}\text { Combination of } \\
\text { factors and levels }\end{array}$} & \multicolumn{4}{|c|}{ Factors } & \multirow{2}{*}{$\begin{array}{c}\text { Specific Wear Rate } \\
(\mathrm{SWR}) \times 10^{-3} \mathrm{~mm}^{3} / \mathrm{kg} \cdot \mathrm{m}\end{array}$} \\
\hline & & $\mathrm{A}$ & $\mathrm{B}$ & $\mathrm{C}$ & $\mathrm{D}$ & \\
\hline 1 & A1B1C1D1 & $\mathrm{PF}$ & 1 & 0.6 & 500 & 0.761 \\
\hline 2 & A1B2C2D2 & $\mathrm{PF}$ & 2 & 1.2 & 1000 & 1.282 \\
\hline 3 & A1B3C3D3 & $\mathrm{PF}$ & 3 & 1.8 & 1500 & 2.734 \\
\hline 4 & A1B4C4D4 & $\mathrm{PF}$ & 4 & 2.4 & 2000 & 3.834 \\
\hline 5 & A2B1C2D3 & $\mathrm{JF}$ & 1 & 1.2 & 1500 & 2.984 \\
\hline 6 & A2B2C1D4 & JF & 2 & 0.6 & 2000 & 2.525 \\
\hline 7 & A2B3C4D1 & $\mathrm{JF}$ & 3 & 2.4 & 500 & 2.338 \\
\hline 8 & A2B4C3D2 & $\mathrm{JF}$ & 4 & 1.8 & 1000 & 4.321 \\
\hline 9 & A3B1C3D4 & MF & 1 & 1.8 & 2000 & 2.945 \\
\hline 10 & A3B2C4D3 & MF & 2 & 2.4 & 1500 & 2.238 \\
\hline 11 & A3B3C1D2 & MF & 3 & 0.6 & 1000 & 2.561 \\
\hline 12 & A3B4C2D1 & MF & 4 & 1.2 & 500 & 3.234 \\
\hline 13 & A4B1C4D2 & $\mathrm{HF}$ & 1 & 2.4 & 1000 & 2.972 \\
\hline 14 & A4B2C3D1 & $\mathrm{HF}$ & 2 & 1.8 & 500 & 1.731 \\
\hline 15 & $\mathrm{~A} 4 \mathrm{~B} 3 \mathrm{C} 2 \mathrm{D} 4$ & $\mathrm{HF}$ & 3 & 1.2 & 2000 & 3.874 \\
\hline 16 & A4B4C1D3 & $\mathrm{HF}$ & 4 & 0.6 & 1500 & 4.317 \\
\hline
\end{tabular}


$\left(0.761 \times 10^{-3} \mathrm{~mm}^{3} / \mathrm{kg}-\mathrm{m}\right)$ was observed for the combination A1B1C1D1 i.e with fiber type (PF), normal load $(1 \mathrm{~kg})$, sliding speed $(0.6 \mathrm{~m} / \mathrm{s})$ and sliding distance $(500 \mathrm{~m})$. The maximum SWR $\left(4.321 \times 10^{-3} \mathrm{~mm}^{3} / \mathrm{kg}-\mathrm{m}\right)$ was noted for the combination A2B4C3D2 i.e for fiber type (JF), normal load $(4 \mathrm{~kg})$, sliding speed $(1.8 \mathrm{~m} / \mathrm{s})$ and sliding distance $(1000 \mathrm{~m})$.

\subsection{Main effect plots}

From the response table for means (Table 6), it is seen that the factor normal load with delta value (1.982) was considered more significant and hence ranked 1 followed by sliding distance, fiber type and sliding speed with ranks 2 to 4 respectively. Referring to the main effects plot for means (Figure 2), since the slope of the factor normal load is more when compared to the slope of other factors, it can be concluded that normal load has a significant influence on the response i.e. specific wear rate ref $^{6,45}$. Other factors influencing the SWR in their order of significance are sliding distance, fiber type and sliding speed respectively.

Figure 3 shows the main effect plots for $\mathrm{S} / \mathrm{N}$ ratios of individual factors. The vertical axis represents the $\mathrm{S} / \mathrm{N}$ ratios and the horizontal axis represents the control factors. From

Table 6. Response table for means

\begin{tabular}{|c|c|c|c|c|}
\hline Level & Fiber type & Normal load (kg) & Sliding speed $(\mathrm{m} / \mathrm{s})$ & Sliding distance $(\mathrm{m})$ \\
\hline 1 & 2.153 & 2.415 & 2.541 & 2.016 \\
\hline 2 & 3.042 & 1.944 & 2.844 & 2.784 \\
\hline 3 & 2.744 & 2.877 & 2.933 & 3.068 \\
\hline 4 & 3.224 & 3.926 & 2.845 & 3.295 \\
\hline Delta & 1.071 & 1.982 & 0.392 & 1.279 \\
\hline Rank & 3 & 1 & 4 & 2 \\
\hline
\end{tabular}

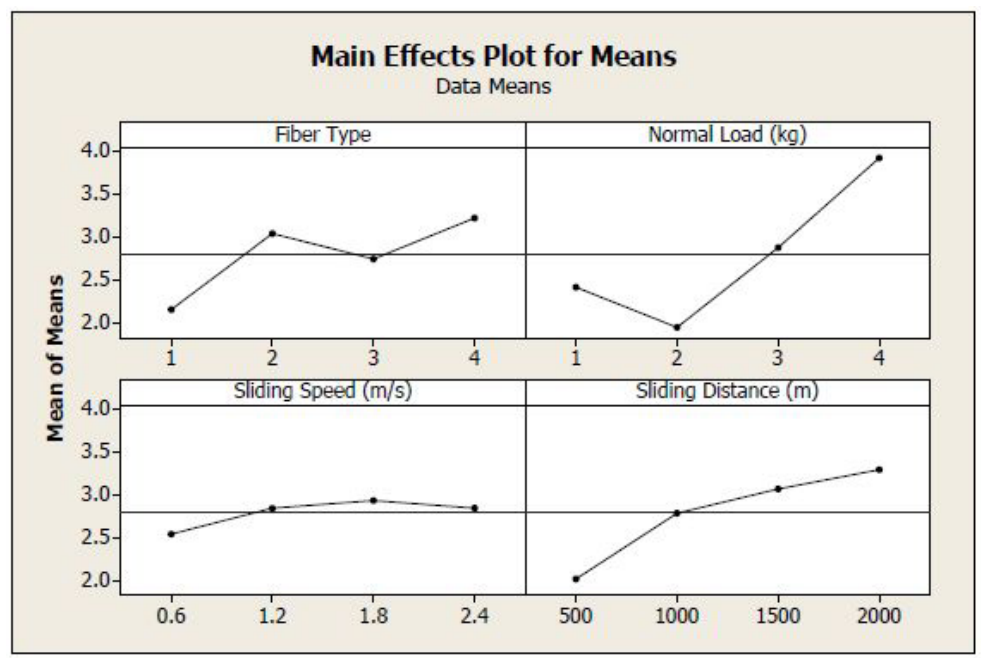

Figure 2. Main effect plots for means.

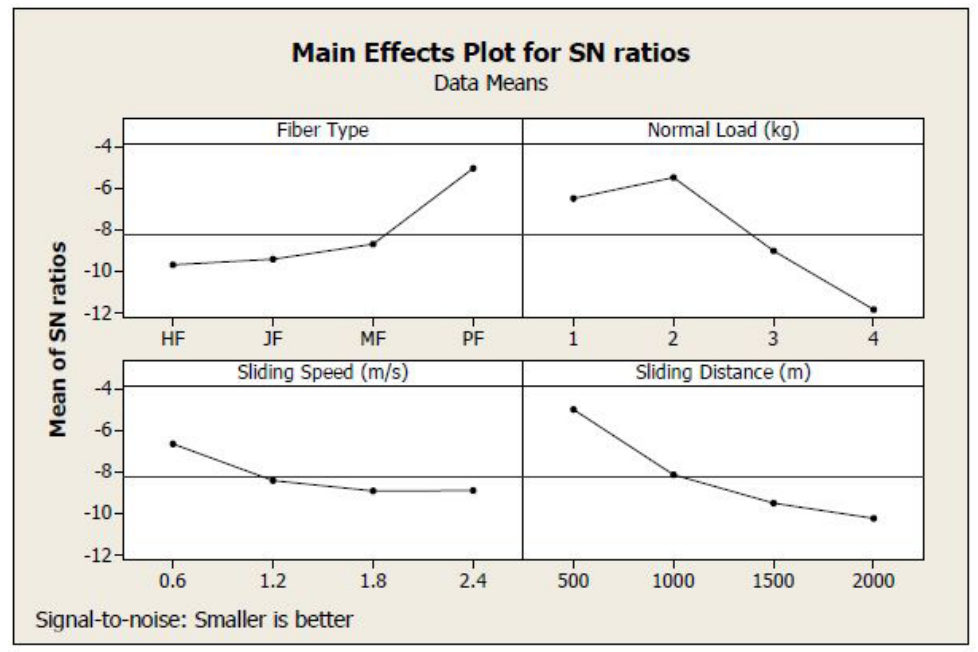

Figure 3. Main effect plots of $\mathrm{S} / \mathrm{N}$ ratios. 
the response table for $\mathrm{S} / \mathrm{N}$ ratios (Table 7), and also from the graphs of main effect plots for $\mathrm{S} / \mathrm{N}$ ratio (Figure 3 ), it is evident that level 1 of fiber type (PF), level 2 of normal load $(2 \mathrm{~kg})$, level 1 of sliding speed $(0.6 \mathrm{~m} / \mathrm{s})$ and level 1 of sliding distance $(500 \mathrm{~m})$ will minimize the response i.e. specific wear rate.

\subsection{Analysis of variance (ANOVA)}

ANOVA is performed on the Taguchi experimental data sets to find the statistical significance of various factors like fiber type, normal load, sliding speed and sliding distance on the specific wear rate of the composites. Confidence level of $95 \%$ was considered for analysis. The results of ANOVA is presented in Table 8. It can be observed that normal load, sliding distance and fiber type (all having $\mathrm{p}<0.05$ ) have high influence on the SWR of the composites ${ }^{20,24}$. The percentage contribution of each of the factor towards SWR are as follows, with normal load contributing by about $56.21 \%$, followed by sliding distance $24.28 \%$, fiber type $17.21 \%$ and sliding speed $2.30 \%$ respectively towards the response.

\subsection{Residual plots}

Figure 4 show the residual plots for the reduced regression model. It can be seen from the Figure $4 \mathrm{a}$ that all the response data points on the plot lie close to the straight line. The normal probability plot of Figure 4a reveals that the residuals generally close to the fit line (mean line) implying that the residuals are normally distributed, which is called linearity. This implies that the experimental SWR data collected are normal and reliable, and a very little deviation from the mean line observed can be neglected. It is seen from Figure $4 \mathrm{c}$ that the residual fall in a straight line, which implies that the errors are normally distributed. Apart from these, Figure $4 \mathrm{c}$ and $4 \mathrm{~d}$ further verify these analysis, indicating that the residuals are random and there are no violations of the independence. In addition, Figures $4 \mathrm{~b}$ and Figure $4 \mathrm{~d}$ revealed that there is no

Table 7. Response table for Signal to Noise Ratios - Smaller is the better

\begin{tabular}{ccccc}
\hline Level & Fiber type & Normal load $(\mathrm{kg})$ & Sliding speed $(\mathrm{m} / \mathrm{s})$ & Sliding distance $(\mathrm{m})$ \\
\hline 1 & -5.049 & -6.492 & -6.636 & -4.991 \\
\hline 2 & -9.407 & -5.492 & -8.403 & -8.125 \\
\hline 3 & -8.685 & -9.011 & -8.899 & -9.483 \\
\hline 4 & -9.673 & -11.821 & -8.877 & -10.216 \\
\hline Delta & 4.625 & 6.329 & 2.263 & 5.224 \\
\hline Rank & 3 & 1 & 4 & 2 \\
\hline
\end{tabular}

Table 8. ANOVA Table for SWR

\begin{tabular}{lccccrcc}
\hline \multicolumn{1}{c}{ Source } & DF & Seq SS & Adj SS & Adj MS & F & P & P\% \\
\hline Fiber type & 3 & 2.6383 & 2.6383 & 0.88794 & 60.67 & 0.003 & 17.21 \\
\hline Normal load $(\mathrm{kg})$ & 3 & 8.6205 & 8.6205 & 2.8735 & 198.25 & 0.001 & 56.21 \\
\hline Sliding Speed $(\mathrm{m} / \mathrm{s})$ & 3 & 0.3533 & 0.3533 & 0.1178 & 8.12 & 0.060 & 2.30 \\
\hline Sliding distance $(\mathrm{m})$ & 3 & 3.7242 & 3.7242 & 1.2414 & 85.65 & 0.002 & 24.28 \\
\hline Error & 3 & 0.0435 & 0.0435 & 0.0145 & - & - & - \\
\hline Total & 15 & 15.3789 & - & - & 352.69 & - & 100.00 \\
\hline
\end{tabular}



Figure 4. Residual plots for specific wear rate. 
noticeable pattern or unusual structure present in the SWR data. These linearity, normality and residuality indicate that the experimental SWR data considered for the regression analysis are reliable and the regression model thus generated is validated.

\subsection{Interaction plots}

The interaction effect of all factors in correlation with the response is presented in Figure 5-10. From the interaction plot of fiber type vs normal load (Figure 5), one can observe an increase in SWR with the increase in normal load (beyond $3 \mathrm{~kg}$ ) for all four types of fibers used in the composites. In

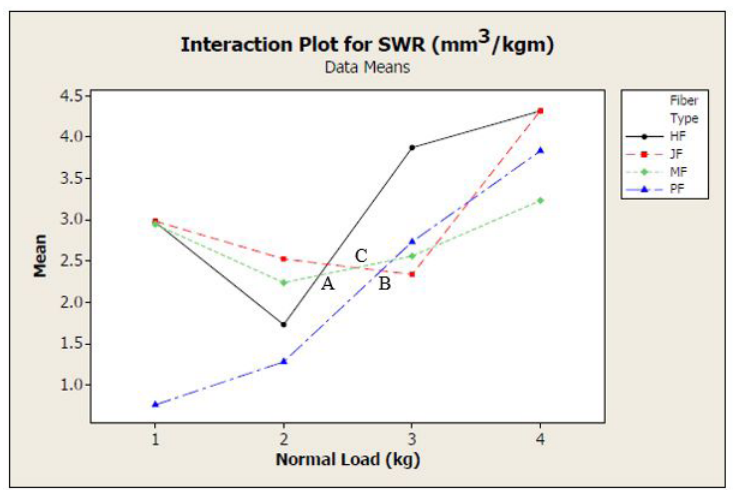

Figure 5. Interaction plot for fiber type and normal load.

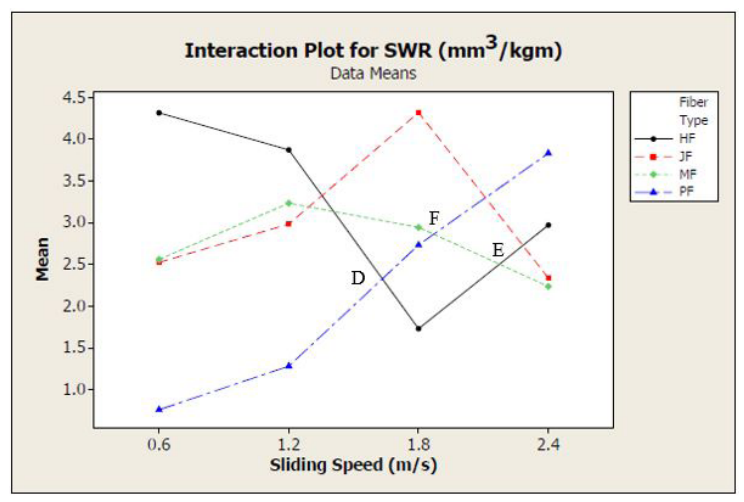

Figure 6. Interaction plot for fiber type and sliding speed.

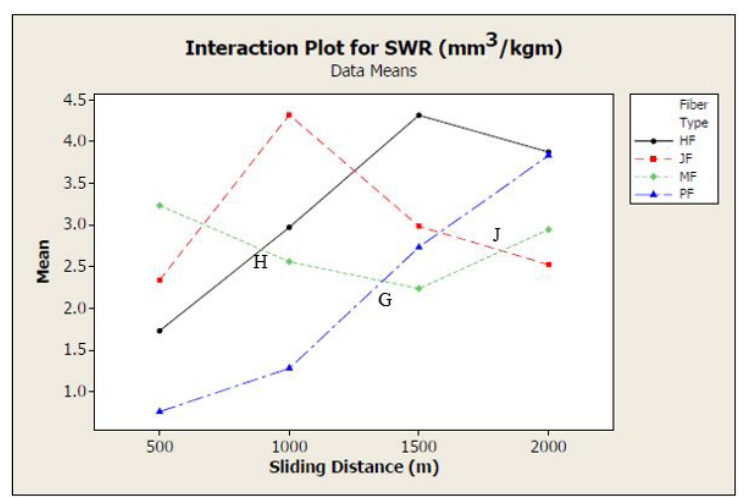

Figure 7. Interaction plot for fiber type and sliding distance. the above interaction plot, minimum SWR is noted for PF fiber composite at normal load of $1 \mathrm{~kg}$ and maximum SWR was seen in case of JF composites with normal load of $4 \mathrm{~kg}$. Also as the loading is changed from $2 \mathrm{~kg}$ to $3 \mathrm{~kg}$, significant interactions were observed at points $\mathrm{A}, \mathrm{B}$ and $\mathrm{C}$. For $1 \mathrm{~kg}$ and $2 \mathrm{~kg}$ normal load condition, the minimum SWR is associated with PF. For $3 \mathrm{~kg}$ normal load minimum SWR is associated with JF and for $4 \mathrm{~kg}$ normal loading the minimum SWR is associated with MF. The results of the above general linear model inferred that the interaction between Fiber type and Normal load wass significant. The interaction at point A (between MF and HF), at point B (between PF and JF) and

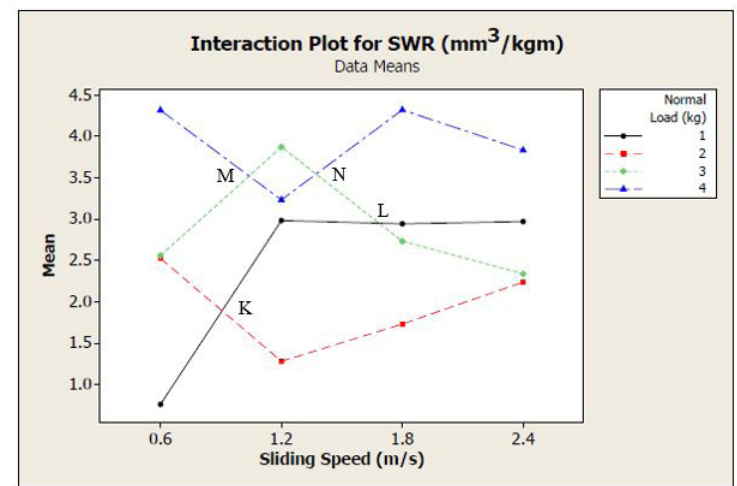

Figure 8. Interaction plot for normal load and sliding speed.

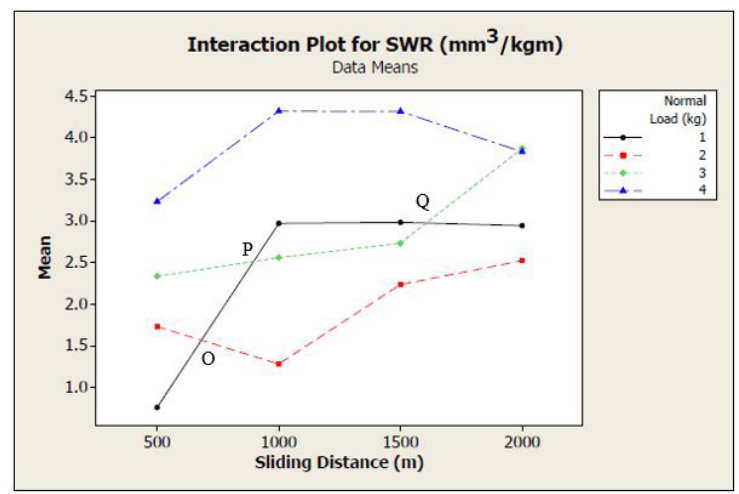

Figure 9. Interaction plot for normal load and sliding distance.

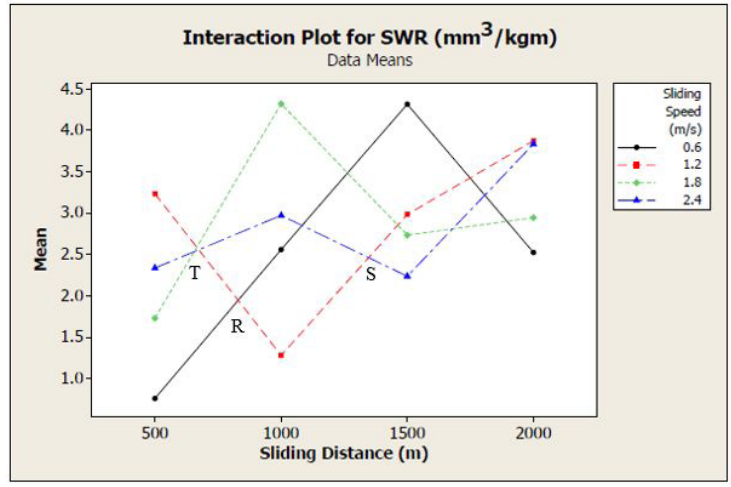

Figure 10. Interaction plot for sliding speed and sliding distance. 
at point $\mathrm{C}$ (between $\mathrm{JF}$ and $\mathrm{MF}$ ) can be used for getting minimum SWRs by considering the interaction of these fibers instantly. Projection of points A, B and C on X axis will give the optimum normal load values respectively to obtain minimum SWR considering the interaction effect of any two fiber types. Similarly, for variation in load from 3 to $4 \mathrm{~kg}$, few more interactions are obtained which are not that critical as it leads to higher SWR.

Considering the interaction plot of fiber type vs sliding speed (Figure 6), the minimum SWR is seen in case of PF composites at sliding speed of $0.6 \mathrm{~m} / \mathrm{s}$ and maximum SWR was obtained in case of JF composites at sliding speed of $1.8 \mathrm{~m} / \mathrm{s}$. With the change in sliding speed from 1.2 to $1.8 \mathrm{~m} / \mathrm{s}$, significant interaction is observed at points $\mathrm{D}$, subsequently $\mathrm{E}$ and $\mathrm{F}$ points are obtained as sliding speed changes from 1.8 to $2.4 \mathrm{~m} / \mathrm{s}$. For a sliding speed of 0.6 $\mathrm{m} / \mathrm{s}$ and $1.2 \mathrm{~m} / \mathrm{s}$, minimum SWR is coupled with PF. On similar lines for sliding speeds of 1.8 and $2.4 \mathrm{~m} / \mathrm{s}$, the minimum SWR is coupled with $\mathrm{HF}$ and MF respectively. The general linear model results shown above indicate that the interaction between fiber type and sliding speed is significant. The interaction at point D (between PF and $\mathrm{HF}$ ), at point $\mathrm{E}$ (between $\mathrm{MF}$ and $\mathrm{HF}$ ) and at point $\mathrm{F}$ (between PF and MF) can be used for getting minimum SWRs by considering these fiber interactions. Projection of point $\mathrm{D}, \mathrm{E}$ and $\mathrm{F}$ on $\mathrm{X}$ axis will give the optimum sliding speed values respectively to obtain minimum SWR for the combined and instantaneous interaction of any two fiber types. Subsequently point E will lead to interaction between $\mathrm{MF}$ and $\mathrm{HF}$ composites, point $\mathrm{F}$ gives interaction between $\mathrm{PF}$ and MF composites. These interactions at points $\mathrm{E}$ and F will lead to higher SWR.

Figure 7 represents interaction of fiber type vs sliding distance. The minimum SWR is observed with PF composites at sliding distance of $500 \mathrm{~m}$ and maximum SWR is obtained at sliding distance of $1000 \mathrm{~m}$ for JF composites. In the same way for sliding distance of 1500 and $2000 \mathrm{~m}$, the minimum SWR is attached with MF and JF respectively. The general linear model results shown above indicate that the interaction between fiber type and sliding distance also has significant effect on the SWR. The fiber interactions at point $\mathrm{G}$ (between $\mathrm{PF}$ and MF), at point $\mathrm{H}$ (between $\mathrm{MF}$ and $\mathrm{HF}$ ) and at point $\mathrm{J}$ (between JF and MF) can be used for getting minimum SWR's. Projection of point G, H and J on X axis will give the optimum sliding distance values to obtain minimum SWR for the combined and instantaneous interaction of any two fiber types mentioned before. Interaction at point $\mathrm{G}$ would be one of the best alternative when a choice between use of MF and PF composites arises.

From the interaction plot of normal load vs sliding speed (Figure 8), a mixture of trends are observed with reference to the SWR. There is an upward trend observed in the SWR initially for sliding speed up to $1.2 \mathrm{~m} / \mathrm{s}$ and for normal loads of 1 and $3 \mathrm{kgs}$. Similarly a downward trend was observed for normal loads of 2 and $4 \mathrm{kgs}$ upto a sliding speed of $1.2 \mathrm{~m} / \mathrm{s}$. In the above interaction plot, minimum SWR is noted at normal load of $1 \mathrm{~kg}$ and maximum SWR was seen for a normal load of $4 \mathrm{~kg}$. Also as the loading is changed from $2 \mathrm{~kg}$ to $3 \mathrm{~kg}$, significant interactions were observed at points $\mathrm{K}, \mathrm{L}, \mathrm{M}$ and $\mathrm{N}$ i.e., for a sliding speed range of $0.6-1.8 \mathrm{~m} / \mathrm{s}$. For $1 \mathrm{~kg}$ normal load condition, the minimum SWR is associated for a sliding speed of $0.6 \mathrm{~m} / \mathrm{s}$. Similarly for 2 and $4 \mathrm{~kg}$ normal loading, the minimum SWR is associated with $1.2 \mathrm{~m} / \mathrm{s}$ and for $3 \mathrm{~kg}$ normal loading, the minimum SWR is associated with $1.8 \mathrm{~m} / \mathrm{s}$. The above general linear model results infer that the interaction between normal load and sliding speed is significant. The interaction at point $\mathrm{K}$ (between 1 and $2 \mathrm{~kg}$ normal load), L (between 1 and $3 \mathrm{~kg}$ normal load), M and $\mathrm{N}$ (between 1 and $4 \mathrm{~kg}$ ) can be used for getting minimum SWRs by considering the interaction of the respective normal loads at a time. Projection of point $\mathrm{K}$ on $\mathrm{X}$ axis will give the optimum sliding speed value to obtain minimum SWR considering the interaction effect of 1 and $2 \mathrm{~kg}$ normal loads. Similarly, for variation in sliding speed from 0.6 to $1.8 \mathrm{~m} / \mathrm{s}$, few more interactions (L, M and N) are obtained which are not that critical as it leads to higher SWR.

From the interaction plot of normal load vs sliding distance (Figure 9), a blend of trends are observed with reference to the SWR. There is an upward trend observed in the SWR initially for sliding distance up to $1000 \mathrm{~m}$ for normal loads of 1, 3 and $4 \mathrm{kgs}$ and a downward trend of SWR is observed for normal load of $2 \mathrm{kgs}$. In the above interaction plot, minimum SWR is noted at normal load of $1 \mathrm{~kg}$ and maximum SWR was seen for a normal load of $3 \mathrm{~kg}$. Also significant interactions were observed at points $\mathrm{O}, \mathrm{P}$ and $\mathrm{Q}$ for a sliding distance range from $500-1500 \mathrm{~m}$. For 1,3 and $4 \mathrm{~kg}$ normal load condition, the minimum SWR is associated for a sliding distance of $500 \mathrm{~m}$ and for $2 \mathrm{~kg}$ normal loading, the minimum SWR is associated with a sliding distance of $1000 \mathrm{~m}$. The above general linear model results infer that the interaction between normal load and sliding distance is significant. The interaction at point $\mathrm{O}$ (between 1 and $2 \mathrm{~kg}$ normal load), P (between 1 and $3 \mathrm{~kg}$ normal load) and Q (between 1 and $3 \mathrm{~kg}$ ) can be used for getting minimum SWRs by considering the interaction of respective normal loads instantly. Projection of point K on X axis will give the optimum sliding distance to obtain minimum SWR considering the interaction effect of 1 and $2 \mathrm{~kg}$ normal loads. Similarly, variation in the sliding distance from 500 to $1500 \mathrm{~m}$ leads to two more interactions (P and Q), which are not taken into account as they lead to higher SWR.

From the interaction plot of sliding speed vs sliding distance (Figure 10), a fusion of trends are observed with reference to the SWR. There is a rising trend observed in the SWR initially for sliding distance up to $1000 \mathrm{~m}$ for sliding speeds of $0.5,1.8$ and $2.4 \mathrm{~m} / \mathrm{s}$. and a sliding trend of SWR is observed for normal load of $2 \mathrm{kgs}$. In the above interaction plot, minimum and maximum SWR is observed for a sliding speed of $0.6 \mathrm{~m} / \mathrm{s}$ for a sliding distance of $500 \mathrm{~m}$ and $1500 \mathrm{~m}$ respectively. Also significant interactions were observed at points $\mathrm{T}, \mathrm{R}$ and $\mathrm{S}$ for a sliding distance range from $500-1500 \mathrm{~m}$. For sliding speed of $0.6,1.8$ and $2.4 \mathrm{~m} / \mathrm{s}$, the minimum SWR is associated for a sliding distance of $500 \mathrm{~m}$ and for sliding speed of $1.2 \mathrm{~m} / \mathrm{s}$, the minimum SWR is associated with a sliding distance of $1000 \mathrm{~m}$. The above general linear model results infer that the interaction between Normal load and sliding distance is significant. The interaction at point $\mathrm{R}$ (between sliding speed of 0.6 and $1.2 \mathrm{~m} / \mathrm{s}$ ), S (between sliding speed of 1.2 and $2.4 \mathrm{~m} / \mathrm{s}$ ) and $\mathrm{T}$ (between three sliding speeds of 1.2, 1.8 and $2.4 \mathrm{~m} / \mathrm{s}$ ) 
can be used for getting minimum SWRs by considering the interaction of respective sliding speeds at once. Projection of point $\mathrm{R}$ on $\mathrm{X}$ axis will give the optimum sliding distance to obtain minimum SWR considering the interaction effect of sliding speed of 0.6 and $1.2 \mathrm{~m} / \mathrm{s}$. Similarly, variation in the sliding distance from 500 to $1500 \mathrm{~m}$ leads to two more interactions ( $\mathrm{S}$ and $\mathrm{T}$ ), which are not taken into account as they lead to higher SWR.

\subsection{Confirmation experiment}

The optimum combination of factors and level obtained from the response table of means and $\mathrm{S} / \mathrm{N}$ ratios (Table 6 and 7) which gives minimum SWR is A1B2C1D1, i.e. fiber type $\mathrm{PF}$, normal load $2 \mathrm{~kg}$, sliding speed $0.6 \mathrm{~m} / \mathrm{s}$ and sliding distance $500 \mathrm{~m}$. Using response optimizer plot (Figure 11) the minimum SWR for A1B2C1D1 combination was predicted to be $0.8277 \times 10^{-3} \mathrm{~mm}^{3} / \mathrm{kg}-\mathrm{m}$. Experiments were conducted using the optimum combination and average of the minimum SWR was found to be $0.7893 \times 10^{-3} \mathrm{~mm}^{3} / \mathrm{kg}-\mathrm{m}$ with an error of $4.64 \%$. Confirmation experiments were conducted for three trials and the average SWR was calculated. Details of confirmation experiments are presented in Table 9.

\subsection{Morphological studies}

SEM micrographs of wear specimen are presented from Figure 12 to 15 . Specimen which exhibited low and high SWR from each type of composites were considered for the analysis. Figure $12 \mathrm{a}$ shows the micrograph of PC composites which were tested under the conditions of $1 \mathrm{~kg}$ normal load, $0.6 \mathrm{~m} / \mathrm{s}$ sliding speed and sliding distance of $500 \mathrm{~m}$. Matrix cracking and de-bonding between the matrix and the fiber were the visible modes of failure. Specimen of PC composites which showed the highest SWR was tested under the conditions of $4 \mathrm{~kg}$ normal load, $2.4 \mathrm{~m} / \mathrm{s}$ sliding speed, for a sliding distance of $2000 \mathrm{~m}$ and the SEM micrograph of the same is shown in Figure 12b. When compared with Figure 12a, relatively more wear marks can be observed along with formation of furrows. Wear marks were formed due to the action of dislodged particles (wear debris) which remain trapped between the wear surface and the hardened disc ${ }^{46}$. Due to friction, heat is generated which softens the wear surface. Trapped debris act as abrasives and due to higher normal load and prolonged wear duration, wear marks and furrows are formed on the softened surface ${ }^{47}$ Fiber matrix de-bonding was also seen but relatively in excess than the PC

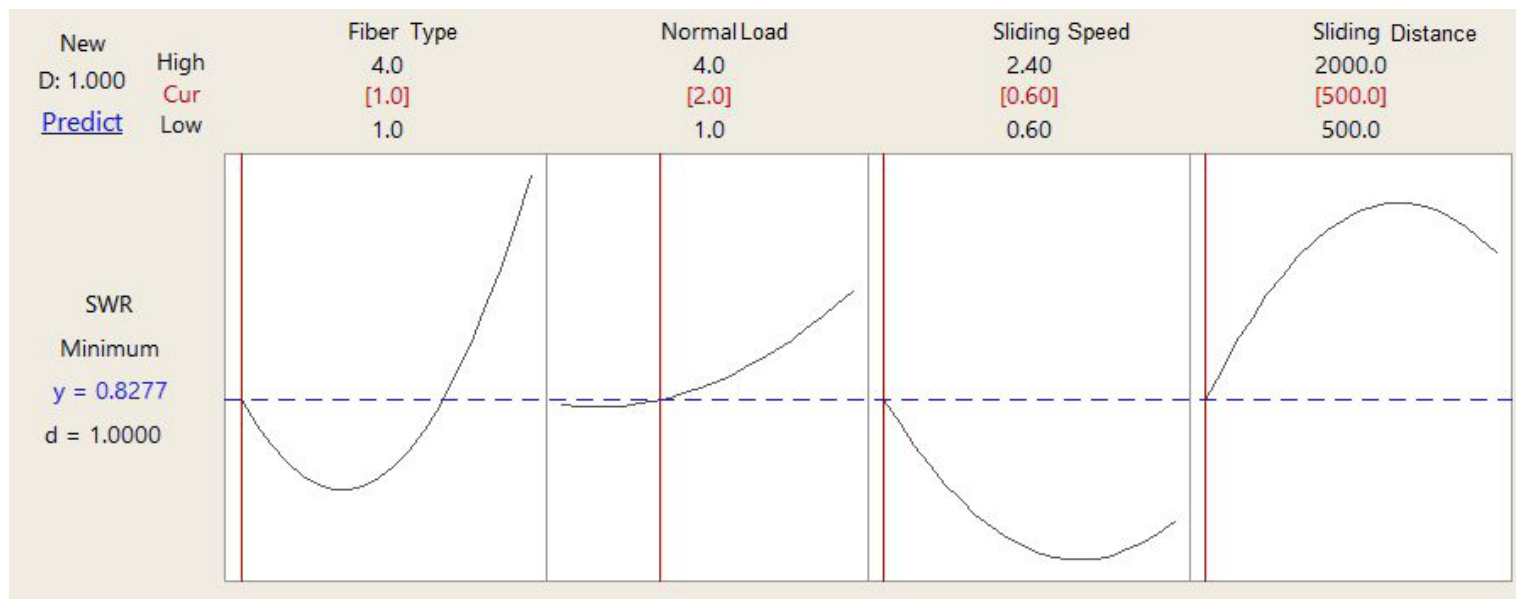

Figure 11. Response optimizer plot for specific wear rate.
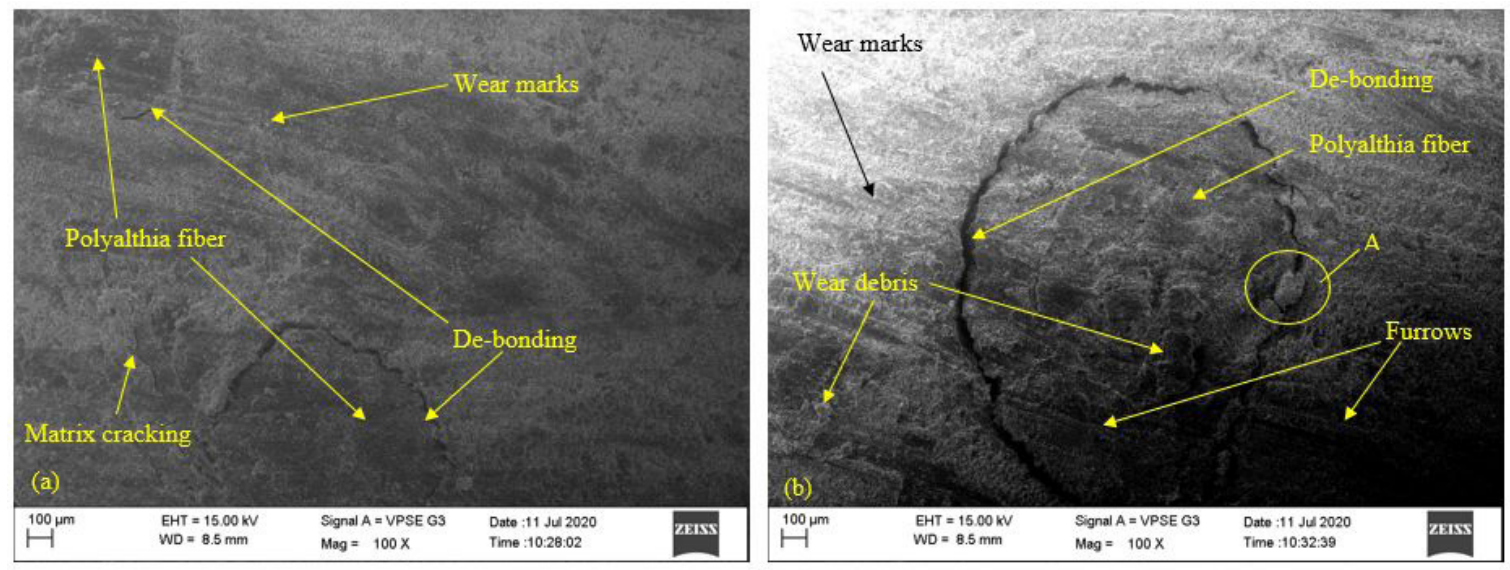

Figure 12. SEM micrographs of Polyalthia composites. 
composites with lowest SWR which can also be attributed to higher interfacial temperature ${ }^{45}$. Wear debris can be seen adhered to the worn out surface including the surface of the fiber. Because of excessive wear, disintegration of the Polyalthia fiber could also be seen (zone A).

SEM micrographs of JC composites are shown in Figure 13. The specimen corresponding to lowest SWR among JC composites (Figure 13a) was tested with normal load of $3 \mathrm{~kg}$, at a sliding speed of $2.4 \mathrm{~m} / \mathrm{s}$ and for a distance of $500 \mathrm{~m}$. Fiber pull-out with matrix cracking were seen as the major mechanisms of wear. Pull-out of fiber is seen to be laterally and that is because the composites were fabricated with chopped fibers oriented randomly. The lateral pull-out of the fiber has left behind an impression on the matrix. Fibers normal to the wear surface is expected to provide better resistance to wear since they don't get dislodged easily when compared to fibers placed laterally (in plane of wear surface). Zone A in Figure 13a shows impressions of secondary fibrils of jute fiber indicating pull-out of the same. From Figure 13b, which corresponds JC composites with highest SWR and tested under the conditions of $4 \mathrm{~kg}$ normal load, sliding speed of $1.8 \mathrm{~m} / \mathrm{s}$ and over a distance of $1000 \mathrm{~m}$; crushing and shearing of jute fiber was seen. Along with fiber shearing, de-bonding between the jute fiber and the epoxy matrix can also be seen. Wear debris could be seen at few places adhered to the worn surface.

Figure 14 a corresponding to MC composites with lowest SWR; tested at a normal load of $2 \mathrm{~kg}$, sliding speed of $2.4 \mathrm{~m} / \mathrm{s}$ and distance of $1500 \mathrm{~m}$ revealed cracking of matrix, shallow wear marks along with formation of furrows at few places. Disintegration and breaking of Mangifera fiber at few places (arrows shown with A) could also be seen. From Figure 14b, which is SEM micrograph of MC composites with highest SWR and tested at normal load of $4 \mathrm{~kg}$, sliding speed of $1.2 \mathrm{~m} / \mathrm{s}$ and over a distance of $500 \mathrm{~m}$; ploughing or formation of crater was seen towards the edge of the specimen ${ }^{48}$. M1,

Table 9. Results of confirmation experiment.

\begin{tabular}{|c|c|c|c|}
\hline \multirow{2}{*}{ Description } & \multicolumn{2}{|c|}{ Optimal Condition } & \multirow{2}{*}{ Error $(\%)$} \\
\hline & Predicted & Experiment & \\
\hline Factors and Level Combination & A1B2C1D1 & A1B2C1D1 & $\begin{array}{ll}--- \\
-\end{array}$ \\
\hline Specific Wear Rate $\left(\mathrm{mm}^{3} / \mathrm{kg}-\mathrm{m}\right)$ & $0.8277 \times 10^{-3}$ & $0.7893 \times 10^{-3}$ & 4.64 \\
\hline
\end{tabular}
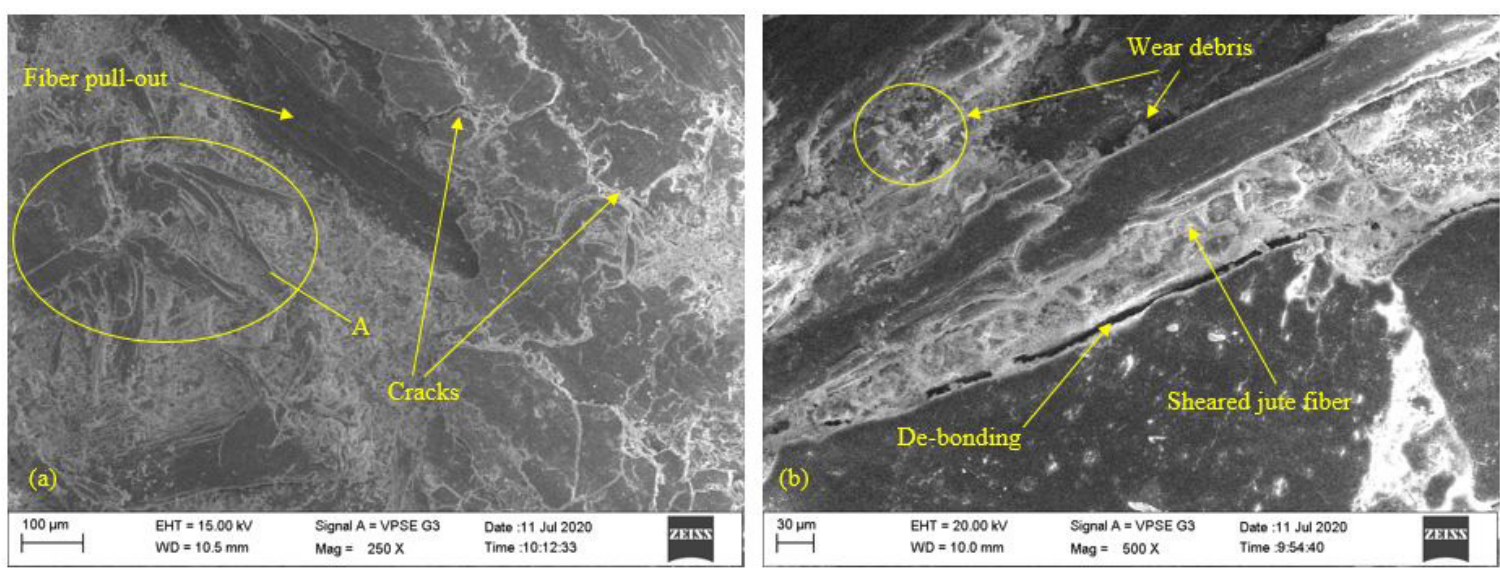

Figure 13. SEM micrographs of Jute composites.
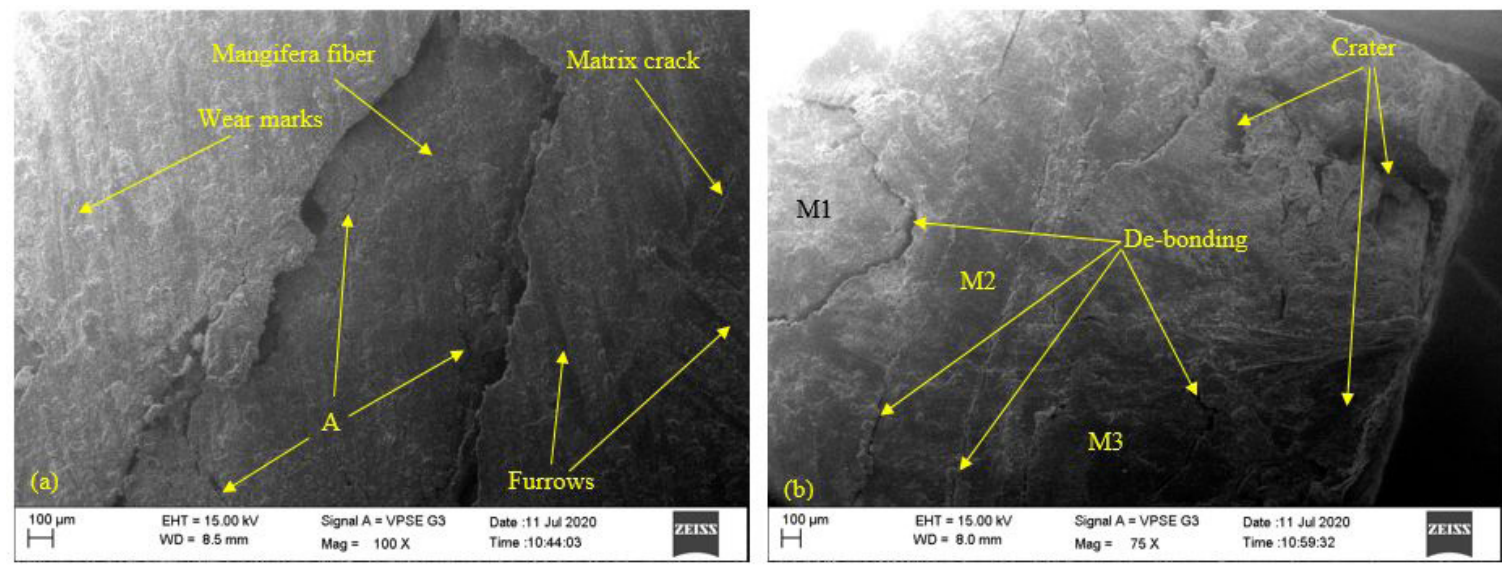

Figure 14. SEM micrographs of Mangifera composites. 


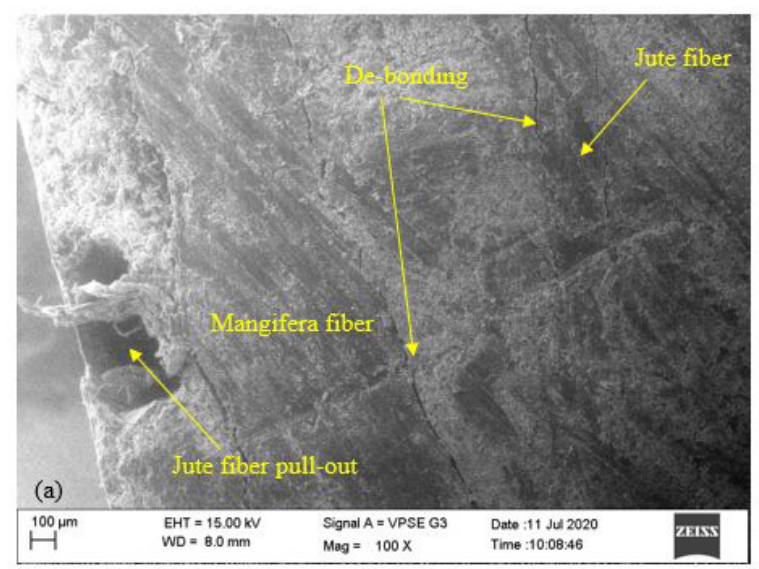

Figure 15. SEM micrographs of hybrid composites.

M2 and M3 are the Mangifera fibers embedded in the matrix out of which $\mathrm{M} 1$ and $\mathrm{M} 3$ are fibers which are normal to the wear surface while M2 is in the plane of the wear surface. De-bonding could be seen at the fiber matrix interface. A unique characteristic of $\mathrm{MC}$ composites as seen from the SEM micrographs is that the fiber surface was not in the same plane as that of the wear surface and was seen to be below the wear surface. This is probably due to the formation of a tribo-film; a film formed with fine dislodged particles of Mangifera fiber and epoxy. This film gets deposited due to thermal softening of the wear surface and acts as a lubricant thereby reducing the wear rate. Similar observations were reported by Rajini et al. ${ }^{23}$ and Singh et al. ${ }^{49}$ At higher loads the film cannot sustain and leads to relatively higher wear. Though, the tribo-film on composites with higher SWR is relatively less thick, it plays a significant role in reducing the SWR. This is unique to composites with Mangifera fibers indicating its lubricating potential. Relatively reduced SWR of MC composites over the others can be attributed to this phenomenon.

Figure 15a shows the SEM micrograph of HC composites with lowest SWR and tested at $2 \mathrm{~kg}$ normal load, at a sliding speed of $1.8 \mathrm{~m} / \mathrm{s}$ and over a distance of $500 \mathrm{~m}$ while Figure $15 \mathrm{~b}$ corresponds to $\mathrm{HC}$ composite specimen with the highest SWR tested under a normal load of $4 \mathrm{~kg}$, at a speed of $0.6 \mathrm{~m} / \mathrm{s}$ and over a distance of $1500 \mathrm{~m}$. Mangifera fiber and Jute fiber (in plane of the wear surface) could be seen. The other Jute fiber which was at normal to the wear surface has pulled-out due to the wearing action resulting in formation of a cavity. Minor de-bonding at the fiber-matrix interface of both the in-plane fibers could be seen. Prominent wear marks, excessive fiber -matrix de-bonding and craters could be seen in Figure 15b.

To summarize, major mechanisms of wear observed from the SEM micrographs (Figure 12 to 15 ) include fibermatrix de-bonding, matrix cracking, formation of furrows and craters, fiber shearing and fiber pull-out. Trapped wear debris results in formation of wear marks on the surface as a combined effect of thermal softening and abrasion. Excessive fiber matrix de-bonding and deeper wear marks were typical to composites with higher SWR whereas in case of specimen with lower SWR, though these mechanisms were seen they were less prominent.

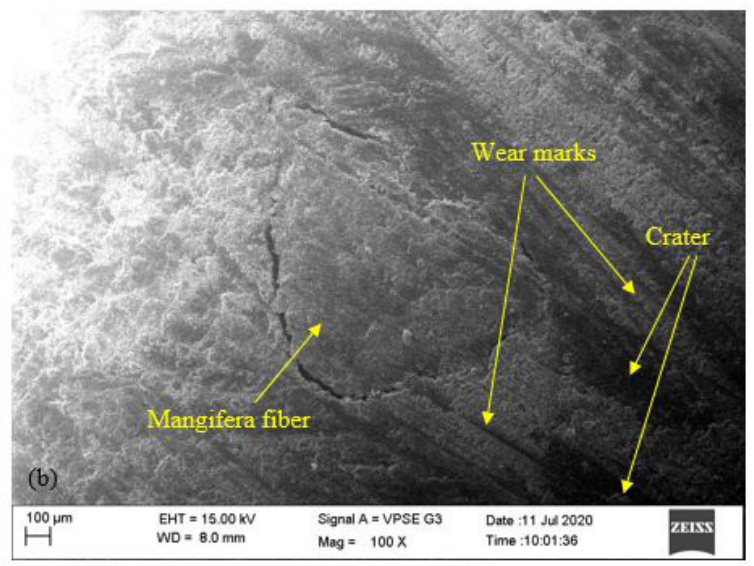

\section{Conclusion}

Following conclusion could be made from the wear performance of Polyalthia Longifolia, Jute and Mangifera Indica reinforced epoxy composites.

- Normal load was found to be the most significant factor and sliding speed the least to minimize the SWR.

- $\quad P F$ as the fiber, normal load of $2 \mathrm{~kg}$, sliding speed of $0.6 \mathrm{~m} / \mathrm{s}$ and a sliding distance of $500 \mathrm{~m}$ was found to be the optimal combination for reduced SWR.

- Percentage contribution of normal load on the SWR was $56.21 \%$, while that of sliding distance was $24.28 \%$, fiber type was $17.21 \%$ and sliding speed was $2.30 \%$.

- $\quad$ ANOVA and residual plots showed goodness of fit for the experimental data while the SWR data of confirmation experiment showed close agreement with the predicted SWR data.

- SEM images showed failure mechanisms like cracks, fiber pull-out, de-bonding between fiber and matrix, cracking of matrix, craters and furrows.

- Composite material studied here can be useful for applications like mud flaps/ mudguards for twowheelers, belt and sprocket guards for machines, floor and parking interlocks.

\section{References}

1. Chawla KK. Composite materials: science and engineering. New York: Springer Science \& Business Media; 2012.

2. Swain PTR, Biswas S. Abrasive wear behaviour of surface modified jute fiber reinforced epoxy composites. Mater Res. 2017;20(3):661-71

3. Nayak SY, Heckadka SS, Sarvade PP, Shenoy KR, Samant $\mathrm{R}$, Kaiser P. Influence of chemical treatment on the physicomechanical characteristics of Tamarind and Borassus fruit fibres-a comparative assessment. Mater Res Express. 2019;6(12):125107.

4. Shenoy Heckadka S, Nayak SY, Joe T, Zachariah NJ, Gupta $\mathrm{S}$, Kumar NVA, et al. Comparative evaluation of chemical treatment on the physical and mechanical properties of areca frond, banana, and flax fibers. J Nat Fibers. 2020;53(2):1-13.

5. Nayak SY, Sultan MTH, Shenoy SB, Kini CR, Samant R, Shah AUM, et al. Potential of natural fibers in composites for ballistic applications-a review. J Nat Fibers. 2020;1-11. 
6. Ravikumar P, Suresh AR, Rajeshkumar G. An investigation into the tribological properties of bidirectional jute/carbon fiber reinforced polyester hybrid composites. J Nat Fibers. 2020;1-11.

7. Karthikeyan S, Rajini N, Jawaid M, Winowlin Jappes JT, Thariq MTH, Siengchin S, et al. A review on tribological properties of natural fiber based sustainable hybrid composite. Proc Inst Mech Eng, Part J J Eng Tribol. 2017;231(12):1616-34.

8. Shivamurthy B, Thimmappa BHS, Monteiro J. Sliding wear, mechanical, flammability, and water intake properties of banana short fiber/ $\mathrm{Al}(\mathrm{OH}) 3 /$ epoxy composites. J Nat Fibers. 2020;17(3):337-45.

9. Chelliah A. Mechanical properties and abrasive wear of different weight percentage of TiC filled basalt fabric reinforced epoxy composites. Mater Res. 2019;22(2):1-8.

10. Yang Y, Deng Y, Li X. Uniaxial compression mechanical properties and fracture characteristics of brucite fiber reinforced cement-based composites. Compos Struct. 2019;212:148-58

11. Chan JX, Wong JF, Hassan A, Mohamad Z, Othman N. Mechanical properties of wollastonite reinforced thermoplastic composites: a review. Polym Compos. 2020;41(2):395-429.

12. Ramesh M, Palanikumar K, Reddy KH. Plant fibre based biocomposites: sustainable and renewable green materials. Renew Sustain Energy Rev. 2017;79:558-84.

13. Mahdi E, Dean A. The effect of filler content on the tensile behavior of polypropylene/cotton fiber and poly(vinyl chloride)/ cotton fiber composites. Materials (Basel). 2020;13(3)

14. Wong KJ, Yousif BF, Low KO. The effects of alkali treatment on the interfacial adhesion of bamboo fibres. Proceedings of the Institution of Mechanical Engineers, Part L: Journal of Materials: Design and Applications. 2010;224(3):139-48.

15. Adeniyi AG, Onifade DV, Ighalo JO, Adeoye AS. A review of coir fiber reinforced polymer composites. Compos, Part B Eng. 2019;176:107305.

16. Gheith MH, Aziz MA, Ghori W, Saba N, Asim M, Jawaid $\mathrm{M}$, et al. Flexural, thermal and dynamic mechanical properties of date palm fibres reinforced epoxy composites. Journal of Materials Research and Technology. 2019;8(1):853-60.

17. Heckadka SS, Nayak SY, Gouthaman PV, Talwar A, Ravishankar VA, Thomas LG, et al. Influence of sawdust bio-filler on the tensile, flexural, and impact properties of mangifera indica leaf stalk fibre reinforced polyester composites. In: MATEC Web of Conferences; 2018; France. Proceedings. France: EDP Sciences; 2018. vol. 144, p. 02024.

18. Sankar I, Ravindran D. Fiber loading and treatment effects on dry sliding wear of Palmyra fruit fiber composites. Sci Eng Compos Mater. 2016;23(2):217-26.

19. Ilanko AK, Vijayaraghavan S. Wear mechanism of flax/basalt fiber-reinforced eco friendly brake friction materials. TribologyMaterials. Surf Interfaces. 2017;11(1):47-53.

20. Chaudhary V, Bajpai PK, Maheshwari S. An Investigation on wear and dynamic mechanical behavior of jute/hemp/flax reinforced composites and its hybrids for tribological applications. Fibers Polym. 2018;19(2):403-15.

21. Raghu MJ, Goud G. Tribological properties of calotropis procera natural fiber reinforced hybrid epoxy composites. Appl Mech Mater. 2019;895:45-51.

22. Mahesha GT, Satish Shenoy B, Vijaya Kini M, Padmaraj NH. Wear behaviour studies on Grewia Serrulata bast fibre reinforced polymer composites. Cogent Engineering. 2018;5(1):1-8

23. Rajini N, Mayandi K, Manoj Prabhakar M, Siengchin S, Ayrilmis N, Bennet $\mathrm{C}$ et al. Tribological properties of cyperus pangorei fiber-reinforced polyester composites (friction and wear behavior of cyperus pangorei fiber/polyester composites). J Nat Fibers. 2019;1-13.

24. Rajeshkumar G. A new study on tribological performance of Phoenix Sp. Fiber-reinforced epoxy composites. J Nat Fibers. 2020;1-12.
25. Kumar S, Patel VK, Mer KKS, Gangil B, Singh T, Fekete G. Himalayan natural fiber-reinforced epoxy composites: effect of Grewia optiva/Bauhinia Vahlii fibers on physicomechanical and dry sliding wear behavior. J Nat Fibers. 2019;1-11.

26. Pokhriyal M, Prasad L, Raturi HP. An experimental investigation on mechanical and tribological properties of Himalayan nettle fiber composite. J Nat Fibers. 2018;15(5):752-61.

27. Kumar S, Prasad L, Kumar S, Patel VK. Physicomechanical and Taguchi optimized abrasive wear behaviour of $\mathrm{KOH} / \mathrm{KMnO} 4 /$ $\mathrm{NaHCO} 3$ treated Himalayan Agave fiber reinforced polyester composite. Mater Res Express. 2019;6(12)

28. Heckadka SS, Nayak SY, Kamath RC, Adarsh SP, Samant R. Characterisation of a novel Polyalthia Longifolia Mid-rib fibers as a potential reinforcement for polymer composites. J Nat Fibers. 2020;1-15.

29. Boggarapu V, Gujjala R, Ojha S. A critical review on erosion wear characteristics of polymer matrix composites. Mater Res Express. 2020;7(2)

30. Milosevic M, Valášek P, Ruggiero A. Tribology of natural fibers composite materials: an overview. Lubricants. 2020;8(4):1-19.

31. Siva I, Jappes JTW, Suresha B. Investigation on mechanical and tribological behaviour of naturally woven coconut sheathreinforced polymer composites. Polym Compos. 2012;33(5):72332.

32. Yousif BF, El-Tayeb NSM. The effect of oil palm fibers as reinforcement on tribological performance of polyester composite. Surf Rev Lett. 2007;14(6):1095-102.

33. Ramesh M, Palanikumar K, Reddy KH. Mechanical property evaluation of sisal-jute-glass fiber reinforced polyester composites. Compos, Part B Eng. 2013;48:1-9.

34. Ramesh M, Palanikumar K, Reddy KH. Influence of fiber orientation and fiber content on properties of sisal-jute-glass fiber-reinforced polyester composites. J Appl Polym Sci. 2016;133(6):1-9.

35. Cavalcanti DKK, Banea MD, Neto JSS, Lima RAA, da Silva LFM, Carbas RJC. Mechanical characterization of intralaminar natural fibre-reinforced hybrid composites. Compos, Part B Eng. 2019; 175:107149.

36. Li M, Pu Y, Thomas VM, Yoo CG, Ozcan S, Deng Y, et al. Recent advancements of plant-based natural fiber-reinforced composites and their applications. Compos, Part B Eng. 2020;200:108254.

37. Sayeed MMA, Paharia A. Optimisation of the surface treatment of jute fibres for natural fibre reinforced polymer composites using Weibull analysis. J Textil Inst. 2019;110(11):1588-95.

38. Amutha V, Senthilkumar B. Physical, chemical, thermal, and surface morphological properties of the bark fiber extracted from Acacia Concinna Plant. J Nat Fibers. 2019;1-14.

39. Nayak SY, Satish SB, Sultan MTH, Kini CR, Shenoy KR, Samant $\mathrm{R}$, et al. Influence of fabric orientation and compression factor on the mechanical properties of 3D E-glass reinforced epoxy composites. Journal of Materials Research and Technology. 2020;9(4):8517-27.

40. ASTM International. ASTM G99-17: Standard Test Method for Wear Testing with a Pin-on-Disk Apparatus. West Conshohocken: ASTM International; 2017.

41. Nanda BP, Satapathy A. An analysis of the sliding wear characteristics of epoxy-based hybrid composites using response surface method and neural computation. J Nat Fibers. 2020;115 .

42. Gupta MK, Srivastava RK. Tribological and dynamic mechanical analysis of epoxy based hybrid sisal/jute composite. Indian J Eng Mater Sci. 2016;23(1):17-44.

43. Basavarajappa S, Chandramohan G, Paulo Davim J. Application of Taguchi techniques to study dry sliding wear behaviour of metal matrix composites. Mater Des. 2007;28(4):1393-8. 
44. Daniel AA, Murugesan S, Manojkumar M, Sukkasamy S. Dry sliding wear behaviour of aluminium 5059/SiC/MoS2 hybrid metal matrix composites. Mater Res. 2017;20(6):1697-706.

45. Singh T, Gangil B, Singh B, Verma SK, Biswas D, Fekete G. Natural-synthetic fiber reinforced homogeneous and functionally graded vinylester composites: effect of bagasseKevlar hybridization on wear behavior. Journal of Materials Research and Technology. 2019;8(6):5961-71.

46. Panda R, Tjong J, Nayak SK, Sain M. Effect of Alkyl Phenol from Cashew Nutshell Liquid and Sisal Fiber Reinforcement on Dry Sliding Wear Behavior of Epoxy Resin. J Nat Fibers. 2017;14(5):747-58.
47. Nirmal U, Yousif BF, Rilling D, Brevern PV. Effect of betelnut fibres treatment and contact conditions on adhesive wear and frictional performance of polyester composites. Wear. 2010;268(11-12):1354-70

48. Kumar S, Prasad L, Kumar S, Patel VK. Physico-mechanical and Taguchi-designed sliding wear properties of Himalayan agave fiber reinforced polyester composite. Journal of Materials Research and Technology. 2019;8(4):3662-71.

49. Singh T, Pruncu CI, Gangil B, Singh V, Fekete G. Comparative performance assessment of pineapple and Kevlar fibers based friction composites. Journal of Materials Research and Technology. 2020;9(2):1491-9. 